C O L A B O R A Ç Ã O E S P E C I A L

\title{
ARQUIVOS DO COMUNISMO E PERSPECTIVAS DE PESQUISA 25 ANOS APÓS A "REVOLUÇÃO DOS ARQUIVOS": UM BALANÇO GLOBAL
}

Communism archives and prospects of research 25 years after the "Archives Revolution": a global overview

BERNHARD H. BAYERLEIN

http://dx.doi.org/10.1590/s2178-14942016000300012

Bernhard H. Bayerlein é historiador e pesquisador senior do Instituto de Movimentos Sociais da Universidade de Ruhr, Bochum, Alemanha (dr.bayerlein@uni-koeln.de).

Palestra proferida pelo autor no CPDOC/FGV em 28 de julho de 2016. 


\title{
Resumo
}

Este texto foi a base da palestra proferida pelo autor no CPDOC/FGV em julho de 2016. Nele é apresentado um panorama da situação e das possibilidades de pesquisa nos arquivos mais importantes para os estudos históricos do comunismo em diversas partes do globo. 0 arquivo da Internacional Comunista na Rússia e o Projeto "Comintern online" são especialmente analisados. A abertura desses arquivos teve um impacto considerável na historiografia nos últimos 20 anos, com efeitos tanto na pesquisa sobre a história do século XX quanto nas políticas de memória.

Palavras-Chave: comunismo; arquivos; memória; historiografia.

\begin{abstract}
This is the paper of the lecture given by the author at the CPDOC/FGV in july 2016. It offers an overview of the present situation and of the possibilities of research in the most important archives for historical studies of communism in different parts of the world. The archives of the International Communist in Russia and the "Comintern online" are specially analysed. The opening of these archives had a considerable impact on historiography in the last 20 years, affecting the study of of the XXth century history as well as memory policies.
\end{abstract}

KeYwORDS: communism; archives; memory; historiography.

\section{RÉSUMÉ}

Le texte a été la base de la conférence donnée par l'auteur au CPDOC/FGV en juillet 2016. II présente une vue d'ensemble de la situation et des possibilités de recherche dans les archives les plus importantes pour les études historiques du communisme dans différentes parties du monde. Les archives de I'Internationale Communiste en Russie et le "Comintern online" sont spécialement analysés. L'ouverture de ces archives a eu un impact considerable sur I'historiographie au cours des 20 dernières années, et ses effets se font sentir sur l'étude de l'histoire du XXème siècle autant que sur les politiques de mémoire.

Mots CLÉs: communisme; archives; mémoire; historiographie. 


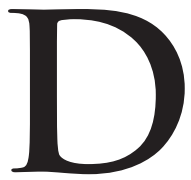

esejo nesta palestra apresentar sob a forma de um balanço intermediário alguns aspectos histórico-arquivísticos ligados ao trabalho com arquivos e à análise de seus resultados. Trata-se de um panorama - muito subjetivo e impressionista - de uma aventura que me intrigou durante as últimas décadas de minha vida de pesquisador. Segui essa vida de pesquisas em primeiro lugar através da Europa, refazendo quase que exatamente o percurso dos peregrinos do caminho de Santiago de Compostela, da Alemanha para a Holanda, Suíça, França, Espanha e Portugal, até o final dos anos 1980, quando os rumos mudaram e o sol nasceu novamente no Leste, pelo menos sob a forma da abertura, ainda que lenta e incompleta, dos arquivos da Rússia. Mas era preciso alterar o sentido geográfico fundamental e ir a Moscou. Recebi uma inspiração particular para escrever este artigo dos colegas e amigos que no inverno de 2016 me permitiram uma estada de três meses de conferências e pesquisas, cheia de simpatia, de amizade e de solidariedade, no Brasil e na Argentina. Muito obrigado, e um grande abraço para todas e todos!

Nas duas primeiras seções desta apresentação vou colocar a questão dos tipos e conteúdos dos arquivos do comunismo demostrando sua heterogeneidade. Do que estamos falando? Neste contexto, discutirei a questão da possibilidade de se falar em uma "revolução dos arquivos". Seguir-se-á um tour d'horizon internacional sobre a situação atual dos arquivos e seu tratamento, os acervos, as fontes de informação, os tipos de acesso e as restrições. Com base no arquivo da Internacional Comunista relatarei em seguida algumas experiências do projeto internacional "Comintern Online" e proporcionarei uma orientação prática para o acesso online aos documentos do acervo do Partido Comunista do Brasil. A abertura desses arquivos tem um impacto considerável para a historiografia, a pesquisa e as políticas de memória. Por isso colocarei em seguida algumas questões quantitativas e qualitativas ligadas ao panorama da pesquisa em nível internacional e esboçarei alguns novos resultados, novas direções e novas metodologias, críticas e problemas da historiografía. 0 tour d'horizon terminará com o esboço de algumas linhas de ação para a identificação, descrição e preservação dos arquivos do comunismo sob a forma de propostas para a comunidade internacional, uma perspectiva que - como espero - poderia inspirar os colegas brasileiros e latino-americanos. 
$\mathrm{O}$ S arquivos do comunismo são como um prisma mundial de uma época. Eles abrangem a história do movimento operário global em centenas de países, as organizações, os movimentos sociais, políticos e culturais, as revoltas, revoluções (ainda que fracassadas), greves, movimentos de solidariedade contra a exploração, a história das repressões desenceadas pelos regimes ditatoriais, as biografias dos atores, incluindo não só as direções comunistas, mas também os níveis regionais e os ambientes locais. Os arquivos do comunismo revelam-se como importantes fontes bastante heterogêneas para a história política, social e cultural do século XX e de seus atores, alçando seus acervos à categoria de patrimônio mundial. Estamos falando de acervos muito diversos que incluem, numa visão transnacional, documentos dos partidos políticos comunistas e outros, dos Estados e países do "socialismo real", os arquivos da Internacional Comunista, do Kominform, das organizações transnacionais de solidariedade, dos movimentos sociais, políticos e culturais, além dos partidos políticos.

Duas premissas antes de nos aprofundarmos. A primeira: muitas vezes, quando se fala em arquivos, não se fala nos resultados das pesquisas. Não vou proceder assim. Desde o início é importante considerar a contradição inerente do mundo dos arquivos como instituição, de um lado, e a prática do pesquisador, do outro. Por isso, na minha conclusão, vou tentar, como dizia Arlette Farge, ir além dos arquivos, capturar o que está dentro deles mas os transcende e vai além, esse "excesso de sentido que está meio dormindo" (Farge, 1989).

Desde o princípio, considero - como segunda premissa - a questão dos arquivos numa perspectiva internacional e o comunismo como fenômeno múltiplo: não só como movimento transnacional ou até internacional, como sistema político, como paradigma cultural-identitário, e até como modo de vida, mas também nas suas diversas orientações ideológicas e programáticas, ou seja, o bolchevismo, o stalinismo e o pós-stalinismo, o trotskismo e as diversas oposicões comunistas "de esquerda" e de "direita", o maoísmo etc.

Nessa dimensão, a conexão com o problema da teoria e prática de uma revolução internacional é capital. Na verdade os arquivos do comunismo permitem uma visão das variedades revolucionárias dos séculos XIX e XX que na história factual produziram uma vasta variedade de infortúnios e fracassos. Por isso, foi com certa razão que meu colega Jan Foitzik, num colóquio com Hermann Weber na Universidade de Mannheim, designou os arquivos do comunismo como a "cesta de lixo da revolução mundial", capaz de revelar os engajamentos, mas também os traumas coletivos, limbos e infernos do século XX. 
E também a heterogeneidade institucional: nos arquivos do comunismo que pertencem aos arquivos políticos (para uma visão geral ver Cook, 2011) encontram-se os tipos jurídicos mais diversos, desde arquivos de Estados, de vários tipos de fundações e instituições ligadas aos partidos políticos (comunistas ou sucessores), até arquivos e coleções privadas, quase sempre dotados de uma riqueza impressionante de espólios pessoais.

Por sua importância quantitativa e qualitativa destacam-se os arquivos russos e das antigas Repúblicas da União Soviética, como os Arquivos do Estado Russo para a História Social e Política (RGASPI) em Moscou, que conservam os arquivos do Comitê Central do Partido Comunista da União Soviética, e o Arquivo da Internacional Comunista, que depois da abertura se tornou um dos centros mais importantes para a história do século XX. Os ex-arquivos soviéticos contêm igualmente boa parte dos patrimônios dos partidos comunistas do mundo inteiro (sobre os arquivos russos e os arquivos do Comintern ver também Kersffeld, 2011; Grimsted, 2011; Petrov, 2011).

Para expor a diversidade e a riqueza e ao mesmo tempo os tipos de procedência mais relevantes dos arquivos do comunismo, gosto citar o exemplo de Berlim como uma espécie de caso ideal, já que na capital da Alemanha uma boa parte dessas procedências é livremente acessível (sobre os arquivos de Berlim e as suas origens ver Müller \& Oldenhage, 2002; Naasner, 2011). São eles:

- Os arquivos federais do Reich alemão que contêm os documentos dos órgãos de vigilância, controle e repressão.

- Os arquivos históricos do Partido Comunista da Alemanha (KPD) no SAPMO, Bundesarchiv.

- Os arquivos das estruturas estatais, dos partidos e movimentos de massa da República Democrática Alemã.

- Os arquivos dos serviços secretos da República Democrática Alemã (1949-1989) que contêm o acervo da polícia política (arquivos da "Staatssicherheit").

- Parte dos arquivos americanos e dos seus serviços de ocupação.

Memo assim, o grande problema é a visão de conjunto: devido à dispersão e à política de arquivos, o pesquisador terá também que considerar os acervos guardados nos arquivos russos. No caso da Alemanha isso diz respeito aos arquivos da Administração Militar Soviética na Alemanha (1945-1949), de um lado. Na Rússia, as procedências especiais incluem também 
os chamados documentos de despojo - os "troféus", sobretudo russos, capturados pela União Soviética no decorrer da Segunda Guerra Mundial e levados para Moscou, que hoje são conservados no Arquivo do Estado Militar da Federação Russa.

$\mathrm{N}$ esse contexto, levantam-se algumas questões a serem tratadas, como a possibilidade de se falar numa "revolução dos arquivos". Nesse ponto, a resposta é clara! Sim! Mesmo que meio abertos e meio fechados, mesmo que ainda estejamos numa fase de transição, é legítimo falar em uma "revolução dos arquivos": dezenas de milhões de documentos já estão de fato disponíveis. Só a Federação Russa, como epicentro dessa revolucão, abriu mais de 500 milhões de documentos de arquivo (Burkhardt, 2016, citando Andrej Artisov, diretor do Rosarkhiv).

A expressão "revolução dos arquivos" é aqui adotada não só num sentido histórico e empírico mas também num sentido ideal-típico e combinatório. Em primeiro lugar, o fim de uma ordem mundial significou que os arquivos se abriram não só no Leste mas também no Ocidente, mesmo que nos últimos 25 anos esse processo proporcione uma imagem muito desigual e desarmoniosa. Tudo está fluindo, todos os tipos de arquivos estão envolvidos, e é difícil obter uma panorâmica adequada dos arquivos dos vários partidos comunistas. Mas aí também um processo de (entre)aberturas se verifica em nível mundial e abre novos horizontes para a história desses países, desde os arquivos do Partido Comunista dos Estados Unidos sob custódia da Tamiment Library em Nova York (http://dlib.nyu.edu/findingaids/html/tamwag/ tam_132/), e do Reino Unido (http://www.bathspa.ac.uk/library/databases/british-online-archives), até os arquivos históricos do Partido Comunista da Alemanha e da França, de alguns países da América Latina, como o Brasil e a Argentina, até a África do Sul e a Austrália. Em muitos casos as diferentes coleções estão em vias de ser recompastas com base nos materiais encontrados nos próprios países, de um lado, e nos arquivos abertos em Moscou, por exemplo nos arquivos do Comintern. Com relação aos arquivos das polícias políticas ou da "segurança do Estado", a situação é especificamente diversa. Basta ter presentes os casos de Portugal, Alemanha, Estados Unidos, Checoslováquia, Ucrânia e Rússia.

Na reflexão sobre esse processo real e combinatório, confesso que relembrei também o conceito Benjaminiano das "dream houses da modernidade" para a arquitetura do século XIX. Isto porque estamos confrontados com o problema de que o caráter transnacional e internacional do comunismo não se reflete na estrutura predominantemente nacional da formação e organização dos arquivos. Lamentavelmente hoje cada Estado tenta encontrar soluções 
nacionais, o que no caso dos arquivos do comunismo revela-se problemático. E por isso temos que diferenciar o conceito de "revolução dos arquivos". Por que não sonhar também com uma dream house dos arquivos no século XXI?

Historicamente, o processo em curso desde 1989 é comparável à abertura dos arquivos do Vaticano. Essa abertura no final do século XIX abriu a história da Idade Média e da Igreja. Os arquivos do comunismo abrem o século XX. Por isso, minha convicção é de que esses arquivos alcançam a categoria de patrimônio da humanidade.

Mesmo parcial, a abertura dos "túmulos dos faraós" está em curso. Dentro do mosaico da história mundial é possível iluminar de diversos ângulos algumas das lacunas que restavam para esclarecer a história desse ensanguentado planeta das revoluções fracassadas do século XX, é possível "recuperar material do interior íntimo da liderança do Kremlin, da Internacional Comunista e dos partidos comunistas, que sob uma fina camada de gírias (...) da 'fala' e do slang ideológico produz um texto claro como dificilmente se encontra em declarações públicas ou papéis diplomáticos" (Koenen, 2015). E mesmo parcial, apesar de tudo, nesse contexto parece um paradoxo, mas de nenhum ditador, seja Hitler, Mussolini ou outros, tantos documentos originais foram publicados como no caso de Stalin (ver mais adiante).

Mas atenção: para a consulta é imperioso sempre olhar para o processo de constituição das procedências respectivas, ver a maneira como os documentos têm sido colecionados e ordenados: no caso dos arquivos do Comintern, por exemplo, os processos de ordenamento, seleção e descrição foram efetuados no auge do poder do império de Stalin. 0 pesquisador precisa de uma espécie de chave para situar os documentos no seu contexto.

\section{4}

Dara abordar a questão da situação atual da "revolução dos arquivos" gostaria de fazer um breve tour d'horizon. A primeira questão pode ser colocada da seguinte maneira: quais são as fontes de informação existentes, os tipos de acesso disponíveis, quais as restrições?

Para abrir a problemática das fontes de informação, é necessário salientar que não existe um instrumento de orientação abrangendo a maioria dos arquivos do comunismo no plano internacional, o que constitui uma grave restrição à acessibilidade global. As razões para isso são múltiplas: ao lado da ausência de plataformas de pesquisa e dos problemas e dificuldades para a sua criação, existe uma colaboração deficitária no nível europeu e global, uma dispersão das pesquisas, uma limitação à história nacional dentro do processo vigente de renacionalização. No nível profissional e deontológico a cooperação interdisciplinar faz falta. A colaboração necessária entre arquivistas, bibliotecários e historiadores ou cientistas 
sociais só raramente se torna realidade. Outro fator interligado é um certo atraso dos digital humanities, isto é, a falta ou também a diversidade de dados estruturais, metadados de todo tipo e instrumentos de ordenamento, inventários, repertórios etc.

Queria também destacar as publicações e edições de fontes muitas vezes sob a forma de coleções. Especialmente três países ocupam um lugar de destaque nesse campo: Rússia, Alemanha e Estados Unidos. Ao mesmo tempo há que sinalizar a falta de uma estratégia internacional de edição de documentos na sua função de ponte central entre a pesquisa e os arquivos, as tradições nacionais nesse campo sendo muito diversas.

Ao lado disso, existe uma grande riqueza de fontes de informação, porém dispersas. Além das páginas na web dos próprios arquivos, existem diversas plataformas arquivísticas europeias, especialmente o "Archives Portal Europe", https://www.archivesportaleurope.net, e a "Europeana", http://www.europeana.eu/portal/de.

Para uma entrada sistemática no mundo dos arquivos russos é recomendável consultar, além dos livros e guias publicados, a página de informação da grande dame dos arquivos russos, Patricia Grimsted, da Harvard University, que inclui também arquivos regionais e museus estatais. Chama-se "Archeo Biblio Base (ABB)" e está publicada no site do Instiruto Internacional de História Social de Amesterdã, http://www.iisg.nl/abb (ver também o relatório sobre os arquivos russos e o trabalho de pesquisa de Jan Plamper, em Plamper, 2003).

Existem revistas especializadas como a International Newsletter of Communist Studies (INCS), http://incs.ub.rub.de, e revistas mais orientadas para as publicações monográficas como a Twentieth Century Communism (London), https://www.Iwbooks.co.uk/free-to-view?type=All\&field_journal_tid=6, a American Communist History (Washington) ou o Jahrbuch für Historische Kommunismusforschung (Berlim). The International Newsletter of Communist Studies online ainda é a única referência digital e também a mais importante para a localização dos arquivos e as novas publicações no campo global dos communist studies. Assim, a edição recente de 2014/2015 contém 342 páginas de novidades, relatórios de projetos, reports, e 17 resenhas.

Só indicaremos aqui os sites das revistas que publicam artigos online com acesso livre. Não incluiremos as revistas especializadas na história do movimento operário, que muitas vezes publicam artigos sobre a história do comunismo. Para América Latina indicamos a título de exemplo Archivos de la Historia del Movimiento Obrero (Buenos Aires), http://www.archivosrevista.com.ar.ca1.toservers.com/contenido/, Políticas de la Memória (CEDINCI, Buenos Aires) e Izquierdas (Santiago de Chile) (ver o Directory of Periodicals on Communist Studies and Connected Areas atualizado a cada ano na International Newsletter of Communist Studies, http://incs.ub.rub.de/index.php/INCS/article/view/480). 
Existem catálogos coletivos, ou Vademecums Contemporary History para arquivos, institutos de pesquisa, bibliotecas, associações e museus nos países da Europa do Leste: https:// www.vifaost.de/fachservice/vademekum/. Publicados para Moldávia, Ucrânia, Eslováquia, Bulgária, Hungria, República Checa, Romênia e Polônia, eles podem ser consultados online na página de informação científica muito útil da Biblioteca Virtual Europa do Leste (Virtuelle Fachbibliothek Ost/VIFA Ost, https://www.vifaost.de) alimentada pela Biblioteca do Estado da Baviera em Munique.

Quero agora entrar mais no concreto e dar uma olhada (mesmo assim necessariamente seletiva) em alguns acervos, coleções, procedências concretas, às vezes espetaculares, e sua acessibilidade digital. Nesta amostra, será dada prioridade ao patrimônio arquivístico de caráter transnacional e relativo em primeiro lugar ao período entre guerras, à primeira fase dos partidos comunistas e à história da Internacional Comunista.

Uma parte importante das fontes russas digitalizadas foram reunidas na página do Comitê dos Arquivos da Federação Russa, que se chama "Documentos da Época Soviética" (Документы советской эпохи), incluindo o acervo de Stalin e os arquivos da Internacional Comunista. 0 Arquivo do Estado (GARF) na sua página web, como também o RGASPI, oferece a consulta de alguns acervos digitalizados: http://www.statearchive.ru, http://rgaspi.org.

No âmbito das iniciativas privadas foi apresentada recentemente uma novidade muitíssmo interessante e importante pela "Sociedade Memorial" da Rússia: http://dostup.memo. ru. Esse projeto web, sob o lema "A cada um seu dossiê pessoal", tenciona auxiliar todas as pessoas que desejaam obter informações contidas nos dossiês pessoais das vítimas do stalinismo na antiga União Soviética.

Contrariamente à situação na Rússia, um processo positivo de abertura dos Arquivos da KGB foi iniciado na Ucrânia. 0 objetivo declarado é, pela chamada "Lei da Descomunização", até o ano de 2017 abrir a integralidade dos documentos da KGB, que deveriam ser entregues ao Instituto de Recordação Nacional e tornar-se acessíveis em formato digital.

Mencionamos Berlim e o caso positivo da Alemanha. De fato, a abertura dos arquivos do comunismo real e da RDA é unica no plano internacional, porque quase de um dia para o outro tornaram-se acessíveis os documentos da polícia secreta - numa nova administração criada para esse fim que no seu arquivo põe à disposição os documentos da "Segurança do Estado" e seus diversos aparelhos: http://www.bstu.bund.de/DE/Archive/_node.html. Uma outra solução muito eficaz foi integrar, por meio da constituição de uma fundação pública, a Fundação Arquivos dos Partidos e Organizações de Massa da RDA, no Arquivo Federal (Stiftung Archiv der Parteien und Massenorganisationen der DDR im Bundesarchiv/SAPMO), https:// www.bundesarchiv.de/bundesarchiv/organisation/sapmo/index.html.de, os arquivos da RDA, 
especialmente os documentos dos partidos políticos e do Estado real-socialista, incluindo os fundos históricos dos partidos comunistas da Alemanha desde a República de Weimar até o fim da RDA. Alguns fundos são acessíveis online: http://www.bundesarchiv.de/benutzung/ digitalisierte_bestaende/index.html.de.

A situação nos países da Europa do Leste também é positiva, sobretudo na questão do acesso, e destaca-se aqui o caso da Romênia, que inclui os arquivos da Segurança de Estado (Söller, 2014; Verdery, 2014).

Para sublinhar a importância transnacional da "revolução dos arquivos" citamos 0 caso dos Estados Unidos. Basta citar a abertura dos arquivos da CIA dentro do "Freedom of Information Act", https://www.cia.gov/library/readingroom/special-collections-archive, e a digitalização dos telegramas dos serviços secretos soviéticos com o codeword VENONA decifrados pelos serviços de contraespionagem ingleses e estadunidenses, https://archive.org/ details/nsia-venona. Entre os arquivos abertos desde longa data mencionamos os Arquivos da Hoover Institution em Stanford, http://www.hoover.org/library-archives/collections, e não podemos esquecer os arquivos Trotski (Trotsky Papers) em Harvard, http://oasis.lib.harvard. edu/oasis/deliver/ hou00301. No Reino Unido mencionamos os documentos cifrados do Comintern decifrados no programa MASK e pesquisáveis no site dos National Archives, http:// discovery.nationalarchives.gov.uk/details/r/C9296.

Entre os países menores é necessário destacar a Dinamarca. Um grupo de pesquisadores escandinavos logrou publicar a integralidade dos dossiês pessoais dos comunistas dinamarqueses contidos no arquivo do Comintern. Por exemplo, o acervo dos "dossiês de quadros" em Moscou contém mais de mil páginas sobre Aksel Larsen (Jørgensen/Sorokin/Friis, 2014). Para dar uma ideia da riqueza do acervo pessoal que contém mais de 25 mil dossiês: o dossiê de quadro do comunista alemão Willi Münzenberg, organizador do Socorro Operário Internacional em 1921 e da Liga Anti-imperialista Contra a Opressão Nacional em 1927, contém mais de 3 mil páginas.

Na digitalização dos arquivos do Partido Comunista nacional, a França constitui hoje o exemplo mais positivo. Graças à equipe da Maison des Sciences de l'Homme (MSH) da Universidade de Borgonha, em Dijon, formada em torno de Serge Wolikow e Jean Vigreux, foi aberto em 2015 o site PANDOR (Portail Digital des Archives Numériques et Données de la Recherche), que contém o programa do projeto Paprik@2f, https://pandor.u-bourgogne.fr/pages/ paprika2f.html. Nesse site, três importantes instrumentos de pesquisa são acessíveis online:

- Os documentos franceses do arquivo do Comintern denominado "Fonds français de I'Internationale Communiste", selecionados a partir de 28 fundos e 3.282 dossiês e que tem 450 mil páginas. 
- O acervo da seção francesa da Internacional Comunista (1917-1947) com 1.004 dossiês digitalizados (do total de 2.400), com aproximadamente 110 mil páginas.

- 0 acervo da direção do Partido Comunista Francês (1922-1939), com 1.659 dossiês e 23 mil páginas, incluindo o Comitê Diretor, o Comitê Central, o Bureau Político e o Secretariado no período entre guerras, cujos originais constam do arquivo do Comintern em Moscou.

Bastante importantes são os demais portais temáticos, bases de dados biográficos, imprensa digitalizada etc., espalhados pelo mundo. Para destacar a importância dessas fontes digitais sinalizamos a título de exemplo o "Portal Online da Imprensa da RDA" do ZZF, Potsdam, e da Biblioteca do Estado, Berlim, http://zefys.staatsbibliothek-berlin.de/ ddr-presse, e também o projeto "Revues directrices communistes internationales 19191989" da MSH de Dijon.

Entre as bases de dados biográficos destacamos o clássico Manual Biográfico de Comunistas Alemães e o compêndio Who was who in RDA?, acessíveis no site da "Bundesstiftung Aufarbeitung", http://www.bundesstiftung-aufarbeitung.de/wer-war-wer-in-der-ddr-\%2363\%3B-1424.html. Os pesquisadores latino-americanos conhecem muito bem o América Latina en la Internacional Comunista, 1919-1943. Diccionario Biográfico de Lazar e Víctor Jeifets, http://www.izquierdas.cl/images/publicaciones/DiccionarioBiorgaficoWeb.pdf, o Diccionario biográfico de la izquierda argentina de Horácio Tarcus (Tarcus, 2007), e a grande obra do Maîtron na França, http://maitron-en-ligne. univ-paris1.fr. Geralmente menos conhecida é uma base da dados biográficos sobre 0 Comintern com mais de 13 mil conjuntos de dados biográficos oferecida pela Universidade de Hanover na Alemanha, http://ts-medien.ub.fu-berlin.de/Citrix/UBCDWeb/\#/launch/ Biographisches \%20Handbuch\%20zur\%20Geschichte \%20der\%20Kommunistischen $\% 20$ Internationale/lx....

Entre os acervos microfilmados sobressai a atividade da Biblioteca do Estado da Baviera, que, com autoria de Freddy Litten, publicou um Repertório dos documentos microfilmados para a história da Rússia e da União Soviética, https://www.bsb-muenchen.de/ mikro/litten.htm.

Se focalizarmos agora algumas tendências negativas, dirigidas contra a abertura, encontraremos em primeiro lugar - além da ausência de metadados não ciŕlicos, o que dificulta a busca transversal - o problema da "sigilização" na União Soviética, acompanhado por um processo de desclassificação muito lento. Embora os números indicados oficialmente sejam de 43.257 documentos para o período de 2011-2015 e as previsões sejam de 46.000 para os 
próximos cinco anos, são números baixos em comparação com os milhões de documentos não desclassificados (Burkhardt, 2016).

O tratamento dos arquivos dos serviços secretos na antiga União Soviética, nas repúblicas soviéticas e nos países da Europa do Leste é extremamente diverso (Kramer, 2012: 204). Assim, os arquivos da KGB de 1917-1991 na Rússia devem permanecer completamente fechados até 0 ano de 2044. Embora a caixa de Pandora do terror soviético tenha sido parcialmente aberta, em parte pelo próprio FSB, sucessor da KGB, assiste-se hoje a um processo reforçado de securitização da história (Burkhardt, 2016). Por um decreto de 4 de abril de 2015, o Comitê de Arquivos da Federação Russa foi diretamente subordinado, juntamente com o Serviço de Inteligência Estrangeira e o Serviço Federal de Segurança (entre outros), ao presidente da Federação. Assim, os materiais de arquivo e as políticas da história foram pelo menos implicitamente declarados de importância estratégica. Nesse contexto, o ato foi percebido como uma advertência ao diretor do Arquivo do Estado da Rússia (GARF), Sergei Mironenko, que era um dos pais da Revolução dos Arquivos. Entre as razões invocadas figura a desmistifação dos documentos dos 28 Panfilovtsy - soldados do Exército Vermelho incluídos na divisão do General Panfilov na batalha de Moscou em 1941, artificialmente transformados em heróis no pós-guerra. A resistência vitoriosa dos Panfilovtsy contra 18 tanques alemães só com granadas de mão e coquetéis Molotov, que até hoje faz parte dos livros escolares na Rússia, foi desmacarada como uma lenda.

Como explica Marc Kramer, do Instituto Woodrow Wilson de Washington, existem razões estruturais que explicam a situação dos arquivos na Rússia, independementemente da política do governo atual: "O ponto básico a ser aqui enfatizado é que o acesso aos arquivos russos sempre foi limitado, mesmo no início da era Yeltsin. De fato, o maior revés para a pesquisa arquivística na era soviética ocorreu bem no começo dos anos 1990, quando Yeltsin decidiu que não abriria vários dos arquivos mais importantes - o Arquivo Presidencial (antigo Arquivo do Politburo), o arquivo da KGB, o arquivo da Agência de Informações Externas, e o Arquivo Militar de Informações." E de fato, até a atualidade, nenhum desses arquivos foi tornado acessível aos pesquisadores acadêmicos (Kramer, 2012: 205 s.).

A esses fatores estruturais é necessário acrescentar uma tendência reforçada à cultura do sigilo no período do governo Putin: documentos previamente abertos foram fechados novamente (os acervos Molotov, Dimitrov, Manuil'skij e outros), documentos sobre a fome na Ucrânia e a pré-história e história da WW2. Constata-se de resto uma intenção manifesta de declarar temas e tradições como "de interesse para a segurança nacional". Ainda não é previsível o fim dessa tentativa de construção de uma imagem nacionalista da Grande Rússia na história, como contrapartida de um pensamento cosmopolita e europeu. 
D ara abordar uma experiência concreta, positiva, destaca-se no cenário o Projeto INCOMKA (International Committee for the Computerization of the Comintern Archives), mais tarde chamado de "Comintern Online", que iniciei junto com o falecido historiador do comunismo latino-americano Jürgen Mothes e o secretário geral do Conselho Internacional de Arquivos, Charles Kecskeméti. Sob os auspícios do Conseil de l'Europe, oito arquivos nacionais junto com a Livraria do Congresso foram reunidos para realizar o maior projeto internacional de digitalização dos arquivos russos até o momento (Bachman, 2005; Bayerlein/ Mouradian/Studer/Wolikow, 2001; Bayerlein/Wolikow, 2001; Haynes, http://www.loc.gov/rr/ european/comintern/comintern-project.html; Kecskeméti, 2004, Kreikamp, 2011).

Depois de ficar off-line por um período de tempo, os documentos são atualmente de livre acesso no site do Rosarchiv. Infelizmente, o único idioma da interface é o russo, e o índice de palavras-chave compilado pelo INCOMKA permitindo a busca transversal ainda não foi transferido para a nova plataforma. No entanto, o fato de 0 arquivo mais crucial da história do comunismo internacional entre guerras estar novamente online é de extrema importância para a comunidade científica internacional. Uma lógica comercial nunca foi a intenção do Projeto INCOMKA (ver a opinião de Kersffeld, 2011: 79). Antes pelo contrário, o projeto estava dirigido contra a comercialização nesse campo, para uma abertura livre. Estão à disposição dos usuários e dos pesquisadores 2.500 páginas de inventários dos arquivos da Internacional Comunista que na época de Stalin foram agregados aos arquivos do Comitê Central do Partido Comunista da União Soviética, mais 1,6 milhão de páginas de documentos numerados, na maioria redigidos em alemão (que era a primera língua oficial do Comintern) e em russo.

Finalmente, essa base contém um índice de nomes com cerca de 170 mil pessoas, na sua esmagadora maioria membros dos partidos comunistas, originárias de quase 100 países (cerca de 30 mil alemães, 18 mil franceses, etc.). De fato, os índices dos dossiês pessoais contidos no arquivo são uma particularidade do projeto. Em colaboração com 140 especialistas de 54 países que retificaram os nomes originais, os 170 mil nomes foram transliterados do alfabeto ciŕlico para o latino pela equipe linguística da Biblioteca do Congresso em Washington. Esses "dossiês de quadros", fascinantes para o historiador, de certa forma são o resultado de um choque mais ou menos traumático entre a vontade de dezenas de milhares de ativistas no mundo inteiro de provar sua convicção revolucionária e sua solidariedade com a Revolução Russa e uma vontade contrária de controle total, paranoico, no stalinismo.

Depois de uma crise na colaboração com os parceiros russos, há alguns meses os dados do Comintern Online podem ser novamente consultados no portal da Internet já mencionado 
do Comitê Russo dos Arquivos, Документы советской эпохи, http://sovdoc.rusarchives. ru/\#main. Além do Comintern Online, essa fonte digital, a mais importante fonte russa, contém 0 acervo do RGASPI, com 300 mil cópias eletrônicas do acervo do Bureau Político do PCUS (1919-1932) e do acervo Stalin (1866-1996), cerca de 250 mil páginas do Comitê Estadual de Defesa (GKO) e cerca de 41 mil documentos do Soviet dos Commissários do Povo (SNK SSSR) no período da Segunda Guerra Mundial.

Um incoveniente do processo de busca é o alfabeto cirílico. Por isso indico três possibilidades que ajudam na utilização da base:

1. Para um guia dos fundos arquivísticos do Comintern em inglês, pode-se recorrer ao site da Library of Congress, https://www.loc.gov/rr/european/comintern/comintern-project.html.

2. Como na situação atual a busca só é possível em russo, seria necessário, pelo menos para os nomes de países, lugares ou pessoas conhecidas, traduzir os keywords, o que funciona bastante bem com o Google tradutor.

3. Se o objetivo é saber se existe um dossiê pessoal sobre um militante comunista específico arquivado em Moscou, existem tabelas de equivalência no site da Library of Congress, https://www.loc.gov/rr/european/comintern/comintern-article.html.

De um lado, os documentos (1,6 milhão) são de livre acesso para a comunidade mundial, de outro, o Comitê russo não utilizava a última versão do INCOMKA com o hipertexto em inglês, com as vantagens respectivas de busca etc., e sim uma versão anterior em cirílico. Estão em curso esforços para restablecer a base com hipertexto em inglês. Nesse ínterim, foi recentemenete publicado um instrumento online de ajuda técnica muito útil para permitir aos pesquisadores que não dominam o russo a consulta da base, sob o título How to navigate the Comintern Archives online. A guide for the Non-Russian Speaker, https://hatfulofhistory. wordpress.com/2016/05/23/how-to-navigate-the-comintern-archives-online-a-guide-for-the-non-russian-speaker/.

A base Comintern tem interesse especial para o Brasil porque o único acervo de um partido comunista nacional digitalizado dentro dela é o do Partido Comunista do Brasil. Mas ela também contém o acervo do Secretariado Latino e do Secretariado Latino-Americano da Internacional Comunista. Para pesquisar na base, eis alguns exemplos de interesse para o Brasil no Secretariado Latino do CEIC (Романский лендерсекретариат ИККИ 19261935), que tem o código РГАСПИ. Ф.495. ОП.32. Ver por exemplo os seguintes documentos: http://sovdoc.rusarchives.ru/\#showunit\&id=133334;tab=img, http://sovdoc.rusarchives. 
ru/\#showunit\&id=95307, http://sovdoc.rusarchives.ru/\#showunit\&id=95226, ou http://sovdoc.rusarchives.ru/\#showunit\&id=153107.

Noacervo do Secretariado de países latino-americanos do CEIC(Латиноамериканский лендерсекретариат ИККИ), que possui o código РГАСПИ. Ф.495. Оп.79 е Ф.495. Оп.101, figura por exemplo o estenograma da sessão do Secretariado dos Países Latino-Americanos sobre os acontecimentos no Brasil em setembro/outubro 1935 que contém 191 páginas e tem o código РГАСПИ. Ф.495. Оп.101. Д.37 http://sovdoc.rusarchives.ru/\#showunit\&id=95307.

Os arquivos do Partido Comunista do Brasil de 1921 até 1940 têm o código РГАСПИ. Ф.495. Оп.29 (Коммунистическая партия Бразилии. 1921-1940) e contêm 144 unidades de arquivo http://sovdoc.rusarchives.ru/\#showunit\&id=95226._Entre outros este acervo contém documentos sobre a Aliança Nacional Libertadora do Brasil no código РГАСПИ. Ф.495. Оп.29. Д.86 (Документы по Национально-освободительному альянсу Бразилии), http://sovdoc.rusarchives.ru/\#showunit\&id=153107.

Uma busca nos inventários dos dossiês pessoais ou de quadros dos comunistas brasileiros revela que no arquivo do Comintern se encontram 386 atas pessoais, começando com Luís Carlos Prestes e terminando com "Nardo" (ver Ф.495, Оп 197, Д.386, busca com vírgulas), http://sovdoc.rusarchives.ru/\#showunit\&id=95400.

Para dar uma ideia comparativo-quantitativa, a busca livre "Brasil" (Бразилия) identifica 305 unidades de arquivo, o índice "Alemanha" (Германия) gera 5.000, enquanto a pesquisa da palavra-chave "Stalin" (Сталин) resulta em 30.000 dossiês ou unidades de arquivamento.

Os fundos do Politburo constituem uma procedência básica para todo tipo de pesquisa. 0 número das decisões protocoladas por reunião do Bureau Político varia aproximadamente de 20 a 100. Este processo de decisão inclui o Comintern e os partidos comunistas, particularmente as seções com maior interesse para a direção soviética e lideranças que vão desde Zinoviev e Trotski, como dirigentes da Internacional, até Bukarin, Molotov e Stalin. E sobretudo até o início dos anos 1930.

0 problema é que os documentos do Bureau Político também foram agregados ao Fundo Stalin e, assim, não são livremente consultáveis. Esta situação foi explicada da seguinte maneira pelo Comitê dos Arquivos da Federação Russa, e já foi criticada no plano internacional: "Segundo o acordo entre o RGASPI e a Yale University Press, o livre acesso a imagens de documentos do fundo Stalin no site 'Documents of Soviet Era' do portal 'Archives of Russia' é permitido somente a usuários com endereço IP da Federação Russa e da República da Bielorrússia. 0 acesso às imagens de documentos do fundo Stalin para outros usuários é oferecido pela Yale University Press. Para maiores informações, favor escrever para support@stalindigitalarchive.com. http://sovdoc.rusarchives.ru/\#showunit\&id=56620;tab=img". 
Sem dúvida alguma, a digitalização do fundo Stalin é positiva. Por outro lado, é absolutamente negativo que também para os arquivos Stalin o acesso esteja bloqueado devido ao contrato com Yale, incluindo os documentos do Bureau Político que não se encontram no site da universidade e cuja digitalização foi financiada pela Associação para a Promoção dos Arquivos (VFA) com sede em Coblença, na Alemanha. Os documentos do Fundo Stalin e do Politburo russo no site russo são consultáveis somente na própria Rússia e na Bielorrússia. Para conseguir o acesso no plano internacional é necessário uma inscrição institucional. Na nova página de Yale "Stalin Digital Archive" http://www.stalindigitalarchive.com/frontend, se explica que os arquivos "estão comercialmente disponíveis numa base institucional" e se oferece um "livre acesso trial ao site". Os preços não são especificados.

No que diz respeito aos arquivos do Comintern, uma outra importante fonte digital foi digitalizada nos anos 2011/2012, também com financiamento da Associação para a Promoção dos Arquivos (VFA): os dossiês pessoais dos membros das Brigadas Internacionais na Guerra Civil Espanhola de 1936 à 1939 (incluindo os voluntários da América Latina acessíveis também no site do RGASPI, http://interbrigades.inforost.org). Mas, aqui também, nem tudo que reluz é ouro, e o acesso só é possível em troca de pagamento. As seis unidades desse acervo contêm 3.365 dossiês num volume de 400.000 páginas, que integram 20.000 dossiês pessoais em espanhol, russo, francês e alemão. 0 acervo contém uma rica coleção de fotografías cuja digitalização está prevista numa segunda fase.

Também no Arquivo do Comintern continuam a existir acervos fechados. Isso inclui os documentos do Departamento de Relações Internacionais (OMS), os já mencionados processos pessoais, os telegramas cifrados, a Comissão Internacional de Controle e também alguma documentação dos secretariados, sobretudo o secretariado de Manuilskij e parte do secretariado de Dimitrov. Alguns desses documentos foram publicados numa edição francesa dos telegramas cifrados (Bayerlein/Narinski/Studer/Wolikow, 2003). Uma parte do acervo Dimitrov foi digitalizada dentro do programa financiado pela VFA. Trata-se de documentos da fase mais obscura do Comintern, de 1935 à 1945, que ainda não revelou todos os seus segredos. A coleção inteira preservada contém aproximadamente 936 unidades de arquivamento, ou 50.000 imagens. Contém a correspondência com os órgãos e seções do Comintern, bem como a correspondência com os órgãos do Estado soviético e do Partido Comunista da União Soviética, documenta as conexões com os órgãos de direção dos partidos comunistas do mundo, sobretudo dos grandes partidos no período da resistência antifascista, das frentes populares e do pacto nazi-soviético, e contém além disso documentos das escolas de quadros do Comintern e documentação sobre as Brigadas Internacionais durante a Guerra Civil Espanhola. 


\section{6}

Sem dúvida alguma, a abertura desses arquivos teve um impacto considerável na histo$\checkmark$ riografia, na pesquisa e nas polítcas de memória. Por isso gostaria de colocar, no final deste artigo, algumas questões ligadas à pesquisa e aos debates. Com a abertura, a historiografia tradicional chegou definitivamente ao fim. Uma nova era de estudos do comunismo, do bolchevismo, do stalinismo e do pós-stalinismo e em certa medida também da esquerda em geral, uma historiografia 2, está suplantando a historiografia 1, que não dispunha ainda dos novos arquivos.

Basta uma análise quantitativa da produção historiográfica no domínio dos "communist studies" para demonstrar a importância transnacional e interdisciplinar desse campo de investigação. Nossa avaliação é que a partir da chamada "mudança" dos anos 90 do século passado foram publicados em todo o mundo 13.000 livros e aproximadamente o mesmo número de artigos de revistas neste campo de estudos. Isso significa 500-800 livros e 600 artigos por ano! http://incs.ub.rub.de/index.php/INCS/article/view/478. Os levantamentos da International Newsletter of Communist Studies mostram também que a dimensão da conjuntura internacional e interdisciplinar nesse campo não diminuiu até hoje. Assim, para os dois anos 2014/2015 foram computados 975 livros publicados em 55 países: http://incs.ub.rub.de/ index.php/INCS/article/view/479. Para o mesmo periódo foram localizados 1.204 artígos de revistas de caráter científico sobre a história do comunismo e tópicos relacionados. Os países mais importantes para a produção científica sobre o comunismo têm sido Rússia, Alemanha e Estados Unidos, seguidos por Reino Unido e França.

É preciso constatar, contudo, uma importante contradição nesse panorama global: essa produtividade que torna os "estudos sobre o comunismo" um dos setores mais importantes das ciências sociais contrasta fortemente com a ausência de institutos e cátedras, de infraestruturas e de espaços universitários que permitam uma investigação livre. As exceções são pouquíssimas: a Stanford University, a London School of Economics ou o Centro de Estudos de História Contemporânea (ZZF) de Potsdam na Alemanha. Cátedras universitárias de história do movimento operário ou da esquerda fazem falta no mundo inteiro. Desse modo, a crise da esquerda se prolonga nas estruturas universitárias... Os " communist studies" estão em muitos casos restritos a instituições de caráter (semi)estatal com vocação política e voltadas para a história, ainda que muitas delas - como os antigos institutos de sovietologia - também tenham sofrido uma redução considerável, como ocorreu por exemplo em seguida à unificação da Alemanha, uma situação que hoje é novamente sentida como calamitosa. 
$\mathrm{N}$ ão somente existem novas pistas e avanços nos conhecimentos e na pesquisa, como assistimos a um avanço quase explosivo na pluralidade de abordagens e acessos. Dentro do campo dos estudos sobre o comunismo revela-se uma preponderância das biografias e das "ego-publicações", memórias, autobiografias, diários etc. A intenção de "personalizar a história e historizar as pessoas" (Whitlock 2007, 20\#) torna-se assim um "instrumento de negociação com a história", posicionando-se muitas vezes contra a narrativa da main stream history (Eakin, 1992: 144). Outro campo de investigação se refere aos mecanismos de decisão política: após 75 anos de domínio das fontes secundárias existe hoje, graças aos arquivos, a possibilidade de identificar e valorizar os atores e grupos de atores e sobretudo os mecanismos de decisão numa perspectiva de história cruzada e transnacional quase como uma realização do sonho da sovietologia, mas ao mesmo tempo superando-o. Os horizontes de pesquisa se alargaram numa perspectiva de história cruzada. Para o período entre-guerras a nova base indispensável é a atuação cruzada de um triângulo de forças, um mecanismo de ação constituído fundamentalmente por três parceiros: a União Soviética de um lado, as organizações comunistas transnacionais e internacionais (o Comintern etc.) como instituições intermediárias, e os partidos comunistas de outro. Os modos deste triângulo de ação e sua interação determinam a história do comunismo numa visão transnacional e formam os novos parâmetros requisitados pela pesquisa.

Ja dissemos que estamos diante de uma grande diversificação e pluralismo de abordagens. Assim, a história social num sentido amplo se encontra complementada pela perspectiva do ator, a prosopografía, os ego-documentos com autobiografías ou diários íntimos, o trabalho da memória. Por enquanto, acessos de tipo culturalista que se distanciem dos novos parâmetros da história política tendem a errar 0 alvo.

A política externa da União Soviética permanece em debate, especialmente na primeira fase da Segunda Guerra Mundial. 0 problema do "nexo entre colisão e confrontação entre a Rússia Soviética e o Reich Alemão, entre comunismo e fascismo no período de 1918 até 1943" é decisivo para o movimento comunista. Até que ponto iam os planos de Stalin para concluir com Hitler um acordo de longo prazo acreditando que este poderia ser utilizado como 'aríete e instrumento pioneiro'? (Koenen, 2015).

Contra uma tendência ao "silenciamento pós-soviético do terror do stalinismo" (Martin Sabrow), a questão da repressão e do terrorismo exercido pelo regime soviético contra miIhões de indivíduos, começando com a geração da Revolução de Outubro, o sistema do Gulag, as crises materiais desenceadas e a questão do controle central do poder pelo secretário geral do partido continuam a ocupar a historiografía. 
E stamos de fato a caminho de uma nova visão transnacional e até global: uma nova história oculta começa a surgir, lentamente... No seu livro Le gout des archives, Arlette Farge escreveu que a prática do arquivo é antes de mais nada um gesto, um ritual, e que se trataria "de ir além dos arquivos, de capturar o que está dentro deles mas naquilo que os transcende e vai além, esse excesso de sentido que está meio dormindo nas frases que o historiador copia e põe em ordem com paciência; este sentido tem que ser buscado sob a desordem aparente dos relatórios, das narrativas, dos fatos e dos acontecimentos" (Farge, 1989). Esse excesso de sentido na história do comunismo com base nos novos documentos de arquivos reflete uma realidade dupla. Assim, num mesmo arquivo encontra-se o reflexo do movimento desenfreado rumo à conquista do céu e ao mesmo tempo um drama, o trauma coletivo e cultural de um caminho percorrido que se transformou numa empresa de "canibalismo político". Assim, os arquivos são a testemunha de um naufrágio global, secular, das grandes organizações e dos partidos políticos do movimento operário no nível internacional, que se tornavam corresponsáveis pelas catástrofes do século... Muitos historiadores, mesmo sem querer, caíram numa armadilha construída intencionalmente pela política arquivística, especialmente no ordenamento dos arquivos e das procedências. Na verdade, os acervos e coleções foram organizados no regime stalinista e pós-stalinista, e com isso nivelaram as profundas descontinuidades de fato existentes entre o bolchevismo original e o stalinismo (inclusive o pós-stalinismo).

Sobretudo, com base nos arquivos e ultrapassando as visões bilaterais e simplistas os movimentos comunistas no planeta devem e podem ser conceitualizados dentro do triângulo de forças determinado pela política soviética, as instâncias internacionais ou bilaterais intermediárias (como o Comintern) e os partidos comunistas e suas estruturas nacionais com seus meios locais.

A primeira impressão que emana dos documentos dos anos 1920 até 40 é a contradição aparente em que os primeiros anos da Internacional Comunista e da União Soviética aparecem como sendo muito mais radicais no sentido político de um internacionalismo revolucionário do que se supunha até então. Em contrapartida, os anos seguintes aparecem como muito mais radicalmente nacionalistas num sentido grande-russo (para evitar o termo mais ideológico de "reacionário") do que se sabia até agora, orientados nitidamente contra a eclosão e organização de qualquer revolução de tipo socialista tanto na metrópole como na periferia.

Essa contradição se reflete bem na vontade política e no postulado moral de Lenin de primazia de uma revolução na Alemanha - e pensem no pacto entre Stalin e Hitler nem 20 anos 
depois, que significou a eclosão da Segunda Guerra Mundial... Assim, cabe destacar na primeira fase, a do bolchevismo internacionalista, não só a vontade de sustentar a revolução alemã, mas também o antirracismo incondicional baseado na multietnicidade, no "affirmative empire" da jovem União Soviética (Martin, 2001). A importância atribuída pelos bolcheviques aos movimentos globais contra o colonialismo e aos movimentos de solidariedade de socorro, antirracistas, anti-opressão, como resposta radical depois do "Wilsonian Moment"; o papel de Berlim e Paris como centros internacionais anti-imperialistas; o papel especial de Berlim como sede da Internacional Comunista da Juventude, do Conselho Internacional das Mulheres e outras iniciativas globais nos primeiros anos da Internacional, mostram a difereça flagrante das análises e do papel da teoria em conjunto no período leninista e no período de Stalin. No segundo momento, já não havia mais lugar para diferentes posições de princípio e luta de ideias. Embora de tamanho e intensidade variável nos diversos países e regiões, a tendência geral foi a de uma mudança fundamental na relação dos partidos comunistas com o Comintern e o PCUS, entre centro e periferia, na segunda metade dos anos 20 e nos anos 30. Nesse sentido, os novos arquivos irão superar a pouca atenção que a historiografía dedicou até o presente à relação entre o Comintern e os partidos comunistas dos países considerados "coloniais" ou "semicoloniais".

Um dos resultados mais importantes da historiografia recente foi de fato mostrar que a história do comunismo não pode ser vista de maneira linear ou uniforme, e sim, muito mais, como uma sequência de voltas e transformações às vezes bruscas, ambivalências e duplicidades. A questão das continuidades e mudanças "dos comunismos" no século XX, a visão da transformação do internacionalismo no período bolchevique e o nacionalismo grã-russo na época de Stalin torna-se crucial para a compreensão das transformações do movimento comunista e para explicar as mudanças operacionais dentro das organizações respectivas. Dentro dessa transformação, a stalinização e a bolchevização foram os mecanismos para, nas estruturas e formas de poder em nível internacional, introduzir uma cópia das estruturas russas/ soviéticas em escala mundial. As transformações também aconteciam nas "frentes culturais", na diplomacia cultural do Estado soviético (Sheila Fitzpatrick), ou na cultura comunista em geral. Os elementos empíricos são comprobatórios no sentido de que em seguida à mitologização da "construção socialista" na União Soviética e à nova regulamentação restritiva no quadro do "realismo socialista" no plano cultural, ampliaram-se as rupturas dos intelectuais, literatos e outros com o "comunismo oficial" em nível gobal. 0 engajamento em prol da liberdade ilimitada da criação artística foi um processo transnacional contínuo nos anos 30 e nas diversas diásporas anifascistas e favoreceu uma transferência na hegemonia dos discursos, uma mudança de paradigma num sentido antistalinista. 
De um ponto de vista "nacional" e global a União Soviética de Stalin evoluiu para uma antítese do socialismo/comunismo a partir da década de 1930, o "socialismo real" integrando-se ao mesmo tempo no sistema mundial (capitalista) vigente, enquanto o principal objetivo da "Revolução de Outubro" e da fundação do Comintern foi justamente o oposto, o contrário. 0 bolchevismo nos anos 30 foi no melhor dos casos substituído por "uma administrção política" que continuava a se chamar partido comunista, mas que se integrou numa espécie de "comunidade de interesses" dentro do sistema mundial. Num olhar retrospectivo, o fracasso definitivo do modelo burocrático não se tornou evidente antes do começo dos anos 50, com as marcas históricas da revolta dos operários alemães em Berlim Oriental em 1953 e a rebelião no Gulag de Workuta no "mar de gelo" do norte da União Soviética no mesmo ano. Nesse sentido, a implosão dos sistemas do "socialismo real" com sua "metafísica do progresso" marcou também o fim definitivo do chamado marxismo do movimento operário (Kurz, 1995).

Lamentavelmente, porém, a ausência de uma base comum de compreensão e de descrição do bolchevismo e do stalinismo e de um quadro comum de referências globais na historiografia, com a implosão do "socialismo real", fortaleceu uma espécie de "consenso comum antitotalitário" que relegou ao segundo plano as diferenças entre os vários momentos da soviética e do comunismo internacional. Foi esse o resultado do processo de renacionalização da história que continua a verificar-se, como também da tese do totalitarismo igualando comunismo e fascismo.

Parece-me que a opinião de cada um sobre o bolchevismo e o stalinismo, seja considerando-os como correntes histórico-políticas per se, seja posicionando-se pró ou contra eles, pode variar consideravelmente. Mas pretender uma continuidade substancial, quase igualando o bolchevismo ao stalinismo, me parece absurdo, o novo topos antistalinista do "anticomunismo" na historiografía. Comparações com o sistema capitalista são malvistas por isso. Do outro lado, a revolução dos arquivos teve o efeito positivo para a história social de prevenir o que se poderia chamar uma "nova decentralização do ator e sua subordinação ao poder dos discursos e mentalidades" (Welskopp, 1998: 311).

P ara colocar o problema dos traumatismos dessa história e a questão da perspectivização nas políticas de memória atuais, acrescento aqui algumas reflexões sobre o papel da história do comunismo no trabalho de memória e sua relevância para a memória histórica colectiva.

Neste contexto, uma das observaçoes mais pertinentes é que no nível transnacional, mesmo após o colapso da União Soviética e do mundo do comunismo oficial, a hierarquia dos 
discursos não se modificou fundamentalmente. Apesar dos esforços feitos em um determinado número de países, a impressão dominante que se impõe é a de que a história do comunismo fica exclusivamente nas mãos dos regimes políticos "vencedores da história". Em muitos países, as estratégias de política de memória em relação à história comunista falharam, na Rússia e nos países da Europa do Leste um novo nacionalismo surgiu. Mesmo na Alemanha, onde o potencial da direita é grande, sobretudo na ex-RDA, fala-se já no fracasso do trabalho com a história do comunismo (Scheitern der Aufarbeitung) (Kowalczuk, 2016). As correntes nacionalistas e populistas são ainda mais fortes em boa parte dos países da Europa do Leste. Lá, as atividades de mémória histórica têm grandes problemas, sobre os quais não posso alargar-me aqui. A Rússia é ainda outro assunto. Será necessário abrir ainda mais essas "sepulturas dos faraós" para que se tornem as tumbas das guerras das histórias nacionais oficiais... Juntamente com a política oficial de memória, a historiografia "benévola" também contribui para esse estado das coisas.

Há fundamentalmente duas razões para explicar isso: primeiro, e infelizmente, a renacionalização não para perante os discursos da memória histórica. Atualmente, o que é ameaçador, como Sabrow formula com força, é uma autêntica "guerra civil entre as culturas de memória" no sentido dos novos objetivos nacionais, incluindo os mitos e lendas (Sabrow, 2007: 5). Segundo: o problema é que as políticas nacionais de memória o mais frequentemente se opõem a aberturas desse tipo porque dependem do prisma cultural e do contexto em que ocorrem.

0 problema é que o "processamento do passado efetuado por grupos sociais", em princípio, nas palavras do Sabrow, segue "os padrões de orientação da normalidade" do período respectivo (Sabrow, 2007: 7). Assim, o trabalho de memória histórica mais recente, o tão positivamente aclamado exemplo da Alemanha, também não convenceu. Um processo comum, europeu, praticamente não existe...

Os arquivos tornam palpável novamente que não só o fascismo, mas também - especialmente para o "povo da esquerda" nos países do mundo - o stalinismo pertence às experiências traumáticas fundamentais do século XX. Do outro lado, porém, da abertura em curso dos arquivos, está resurgindo uma história mantida em segredo, uma espécie de contra-história do século XX que não cabe nas narrativas. Não sabemos ainda em que direção este processo vai continuar. So poderá ser bem-sucedido se a história do comunismo, do movimento operário e da esquerda em geral estiver integrada na história e no discurso sobre os traumas do século XX.

Minha convicção é de que essa integração só terá êxito se nós hoje praticarmos 0 dever não só de investigar e relatar mas também e sobretudo de rememorar e tentar ouvir 
o lamento dessa história no sentido de Walter Benjamin. 0 apelo de 1939 de um novo discurso sobre a história que ele lançou no seu testamento político de modo geral não foi ouvido. Embora seja necessário guardar a memória histórica das vítimas que deram a vida por esse ideal, do outro lado é fundamental recordar os traumas coletivos dessa mesma história.

Essa lembrança, esse "alerta para a memória" no sentido do alemão eingedenk sein, em primeiro lugar deveria ser completamente independente da avaliação e da análise e da historiografia dominante e ao mesmo tempo desvalorizar a narrativa como forma preferencial da rememoração. Devemos, portantanto, encontrar essas novas formas de rememorar. Os arquivos desempenham um papel importante neste processo.

\section{0}

P ara terminar este tour d'horizon, eu queria colocar a questão do que seria preciso para garantir a preservação e o acesso livre aos arquivos do comunismo e do internacionalismo, uma perspectiva que também poderia inspirar ou incitar os colegas brasileiros e latino-americanos.

Três linhas de atuação me paracem imprescindíveis:

1. No plano conceitual isso implicaria adotar uma nova filosofia dos arquivos, num sentido forte de patrimônio, mas na verdade de mediador para a rememoração no sentido de Walter Benjamin.

2. No plano metodológico, em função sobretudo da enorme quantitade de documentação, impõe-se um acesso no sentido da históire sérielle de Pierre Chaunu, para fazer transparecerem as transformações (Chaunu 1978) e, como dizia Foucault, as "descontinuidades" (Foucault, 1969: 36).

3. Da parte dos atores da comunidade internacional, isso implica um novo engajamento comum, uma nova cultura de cooperação transdisciplinar entre pesquisadores, arquivistas, bibliotecários, museólogos etc.

Seguindo essas linhas me parece necessário um novo projeto transnacional e uma campanha internacional de preservação e de descrição dos arquivos do comunismo. Essa campanha deveria se iniciar com algumas realizações de base, no sentido da localização e identificação dos arquivos

1. Constituir e reunir uma rede internacional de compartimentação de recursos (Ressource Sharing Network) para os arquivos a fim de iniciar uma grande campanha 
de preservação e digitalização dos acervos buscando um financiamento junto às instituições internacionais e transnacionais competentes.

2. Uma ideia, como ponto de partida para atrair um maior interesse da opinião pública internacional, poderia ser a campanha que visa a incluir os Arquivos do Comintern no patrimônio documental do registro da "Memória do Mundo" da Unesco e do Conselho Internacional dos Arquivos.

3. Identificar os arquivos e acervos dos partidos comunistas e organizações internacionais no nível nacional e internacional, reunir os inventários existentes traduzindo-os para o inglês e elaborar um guia eletrônico mundial dos arquivos e das fontes do comunismo. Cada país interessado pode começar desde já a reunir e centralizar os dados necessários. Uma conferência internacional de trabalho do RSNW poderia reunir os contribuintes.

4. Na realização do projeto, seria necessário superar a perspectiva euro-americana do comunismo para dar uma especial atenção aos países coloniais e semicoloniais da América Latina, Ásia, do mundo árabe e da África.

Com os meios técnicos à disposição hoje seria possível alcançar esses objetivos. Uma vez alcançadas as metas descritas nos pontos 1-4, a perspectiva seria preparar um programa internacional de digitalização e preservação, e para tanto construir uma nova plataforma multilinguística e multidisciplinar.

\section{REFERÊNCIAS BIBLIOGRÁFICAS}

BACHMAN, Ronald D. The Comintern Archives Database: bringing the Aachives to scholars. Slavic \& East European Information Resources, Stanford CA, vol. 6, n. 2/3, 2005, p. 23-36.

BAYERLEIN, Bernhard H.; MOURADIAN, Georges; STUDER, Brigitte \& WOLIKOW, Serge. Les Archives du Komintern à Moscou. Vingtième Siècle. Revue d'Histoire, Paris, n. 61, 1999, p. 126-132.

BAYERLEIN, Bernhard H. \& WOLIKOW, Serge. A story the world wants to know. The computerization of the Comintern Archive's International Project - guided by the Council of Europe, the International Council of Archives and the Federal Archive Service of Russia. The International Newsletter of Communist Studies, n. 14, 2000/2001, p. 532-537. http://incs.ub.rub.de/index.php/INCS/issue/viewlssue/59/15.

BAYERLEIN, Bernhard H.; NARINSKI, Mikhail; STUDER, Brigitte \& WOLIKOW, Serge (eds). Moscou-Paris-Berlin. Télégrammes chiffrés du Komintern. 1939-1941. Direction éditoriale Denis Peschanski. Paris: Tallandier, 2003.

BURKHARDT, Fabian. "Securitization" von Geschichte? Russlands Archivagentur Rosarchiv in der Präsidentenvertikale. Erinnerungskulturen. Erinnerung und Geschichtspolitk im östlichen und südöstlichen Europa, Munique/Regensburg, 30.4.2016 http://erinnerung.hypotheses.org/745 
CHAUNU, Pierre. Histoire quantitative et histoire sérielle. Paris: Armand Colin, 1978.

COOK, Chris (ed.). The Routledge Guide to European Political Archives. Sources since 1945. Abingdon e.a.: Routledge, 2011.

EAKIN, Paul John. Touching the world. Reference in autobiography. Princeton University Press, 1992.

FARGE, Arlette. Le goût des archives. Paris: Le Seuil, 1989.

FOUCAULT, Michel. L'archéologie du savoir. Paris: Gallimard, 1969.

GRIMSTED, Patricia Kennedy. Archival transition in Russia and the legacy of displaced European archives. Solanus, London, vol. 22, 2011, p. 185-200.

HAYNES, John: Communist International (Comintern) Archives Project. The INCOMKA Project, The Library of Congress, Area Studies, European Division. http://www.loc.gov/rr/european/comintern/comintern-project.html JØRGENSEN, Jesper; SOROKIN, Andrei \& FRIIS, Thomas Wegener (reds.). Datskije kadry Moskvy v stalinskoje vremja. Izbrannyje dokumenty iz litjnykh del v arkhive Kominterna. Danske Moskvakadrer i Stalintiden Udvalgte dokumenter fra de danske personsager i Kominterns arkiv. Odense: Syddansk Universitetsforlag, 2014.

KECSKEMÉTI, Charles. Presentation of the Comintern Archives Project to The Bureau of the Steering Committee for Culture of the Council of Europe, Strasbourg, 15 march 2004. The International Newsletter of Communist Studies vol. 10, n. 17, 2004, p. 11-15. http://incs.ub.rub.de/index.php/INCS/issue/view/56.

KERSFFELD, Daniel. Del esoterismo al marketing. Aproximaciones en torno a los archivos de la Comintern. Íconos. Revista de Ciencias Sociales, Quito, n. 41, 2011, p. 73-88. http://www.flacso.org.ec/docs/i41 kersffeld.pdf.

KOENEN, Gerd. Interna aus einem welthistorischen Trauerspiel. Frankfurter Allgemeine Zeitung, Frankfurt am Main, 21.7.2015.

KOWALCZUK, Ilko-Sascha. Historikerstreit über DDR-Forschung. Die Aufarbeitung ist gescheitert. taz.die tageszeitung, Berlim, 20.4.2016.

KRAMER, Marc. Archival policies and historical memory in the post-soviet era. Demokratizatsiya. The Journal of Post-Soviet Democratization, Washington DC, vol. 20, issue 3, 2012, p. 204-215. https://www.gwu. edu/ ieresgwu/assets/docs/demokratizatsiya\%20archive/GWASHU_DEMO_20_3/Y264633728186364/ Y264633728186364.pdf

KREIKAMP. Hans-Dieter. Das Komintern-Projekt. Mitteilungen aus dem Bundesarchiv, Berlim, n. 1, 2011, p. 11-15. http://www.bundesarchiv.de/imperia/md/content/bundesarchiv_de/oeffentlichkeitsarbeit/fach-publikationen/mitteilungenausdembundesarchiv/barch_mitteilungen_1_2011.pdf

KURZ, Robert. Postmarxismus und Arbeitsfetisch. Zum historischen Widerspruch in der Marxschen Theorie. Krisis, Nuremberga, n. 15, 1995. Versão portuguesa em http://www.obeco-online.org/rkurz136.htm.

MARTIN, Terry. The affirmative action empire. Nations and nationalism in the Soviet Union 1923-1939. Ithaca: Cornell University Press, 2001.

MÜLLER, Michael \& OLDENHAGE, Klaus. Der Weg zur Stiftung Archiv der Parteien und Massenorganisationen der DDR im Bundesarchiv. Skizzen einer Chronologie. Mitteilungen aus dem Bundesarchiv, vol. 10, n. 1, 2002, p. 5-13.

NAASNER, Walter. Das Zentrale Staatsarchiv - Nationalarchiv der DDR. Organisation, politische Funktion, Quellenüberlieferung. Zeitschrift für Geschichtswissenschaft, Berlim, vol. 59, n. 2, 2011, p. 138-58. 
PETROV, Nikita. Soviet State security archives and their exploitation for political aims. Solanus, London, vol. 22, 2011, p. 220-28.

PLAMPER, Jan. Archival revolution or illusion? Historicizing the Russian Archives and our work in them. Jahrbücher für Geschichte Osteuropas, Regensburg, Neue Folge, vol. 51, n. 1, 2003, p. 57-69. http://www.jstor. org/stable/41051001.

SABROW, Martin. Die Lust an der Vergangenheit. Kommentar zu Aleida Assmann. Zeithistorische Forschungen/Studies in Contemporary History, Potsdam, n. 4, 2007, 386-392. http://www.zeithistorische-forschungen. de/16126041-Sabrow-3-2007.

SÖLLER, Carola. Im Spannungsfeld von 'nationalen' und 'europäischen' Ansprüchen? Eine Betrachtung des Nationalen Rates für das Studium der Securitate-Archive in Rumänien. Jahrbuch für Historische Kommunismusforschung, Berlim, 2014, p. 107-124.

TARCUS, Horacio (dir.). Diccionário biográfico de la izquierda argentina. De los anarquistas a la "nueva izquierda" (1870-1976). Buenos Aires: Emecé, 2007.

VERDERY, Katherine. Secrets and truths: ethnography in the Archive of Romania's Secret Police. Budapest: Central European University Press, 2014.

WELSKOPP, Thomas. Klasse als Befindlichkeit? Vergleichende Arbeitergeschichte vor der kulturhistorischen Herausforderung. Archiv für Sozialgeschichte. Bonn, vol. 38, 1998, 301-336.

WHITLOCK, Gillian. Soft Meapons. Autobiography in transit. Chicago: University of Chicago Press, 2007. 